\title{
The Rationale of Continuous Assessment for Development of Competencies in Tanzania Secondary Schools
}

\author{
Selina Mkimbili, Septimi Kitta* \\ Department of Educational Psychology and Curriculum Studies, Mkwawa University College of Education \\ ${ }^{*}$ Corresponding author email: sekitta@yahoo.com \\ Received: 10 April 2019 / Revised: 01 June 2019 / Accepted: 08 July 2019 / Published: 19 July 2019

\begin{abstract}
This paper attempts to illuminate the rationale of continuous assessment for competence development in secondary schools in Tanzania. Although, the curriculum for secondary schools in Tanzania has changed from content-based to competency-based, most teachers in secondary schools are still practicing traditional pen-and-pencil continuous assessment which is far from developing competence in students. There is a dire need for revising the assessment procedures, particularly continuous assessment to ensure the attainment of better competence level among students and realisation of high quality education in Tanzania. This paper examines the rationale of continuous assessment for competence development, as well as the challenges of implementing it. This paper recommends capacity building for secondary school teachers on competence-based assessment, so as to enable them to engage in authentic continuous assessment.
\end{abstract}

Keywords: Competence, continuous assessment, competency-based curriculum

\section{Introduction}

Teaching today has shifted from traditional teacher-centred to Constructivist learner-centred approach to accommodate for the advancement of science and technology (Crawford, 2014). Learner centred approach to teaching require learner to become actively engage in science learning, and not only receiver of the information (Crawford, 2014; Mkimbili, 2018). In this approaches learners are engaged in critical thinking skills and problem solving (Crawford, 2014; Mkimbili, 2018). Leaners that are educated based on this constructivist approach can apply the acquired knowledge in science for solving various problem in the society and are able to participate in various decision on controversial issues (Crawford, 2014). Learner centred approach to teaching is adapted in most African countries (Ogunniyi \& Rollnick, 2015) including Tanzania (Mkimbili, 2018). In Tanzania, the ministry responsible for education, that is, the then Ministry of Education and Vocational Training (MoEVT) and through, Tanzania Institute of Education (TIE), reviewed school curricula at all levels of education. The exercise was done from 2004 to 2008. In 2004, the review was done for pre-primary and primary schools curricula, whereas in 2005 the review was done for ordinary level secondary school (O-level) curriculum. For advanced secondary school education (A-level), the review was done in 2008. For Teacher Education programmes, that is certificate and diploma programmes, the review was done from 2007 through 2008. These reviews were aimed at shifting the teaching and learning paradigm from content-based to competency-based (MoEV, 2007). There were a number of factors that necessitated this shift. One of the major factors was that graduates from contentbased curriculum could not demonstrate the competencies that could help them cope with local, national and global market demands. Thus, the revised curriculum is aimed at enabling them to acquire competencies in addressing current and future national goals, global demands and challenges in the ever changing human needs. Besides, the revised curriculum emphasises on teaching effectiveness in the use of interactive, participatory teaching and learning approaches in a child friendly environment. In the curricula, there are 
six areas of competency that were addressed. These include communication, numeracy; creativity and critical thinking; technology, interpersonal relationships and independent learning.

Educational goals and objectives can only be attained when assessment procedures match with curriculum goals (Kapambwe, 2010). Retaining traditional assessment strategies for a competence-based and learnercentered curriculum can limit the attainment of new curriculum goals. It is important to devise assessment strategies that can enhance the attainment of established curriculum goals. For effectively engage learners in problem solving and critical thinking the assessment procedures need to be revised to accommodate competences assessment by engaging them in formative assessment (Osborne \& Dillon, 2008).

In the Tanzania context, assessment is either formative or summative. Formative assessment is similar to continuous assessment which is integrated in the teaching and learning process. The goal of formative assessment is to provide constructive feedback to enhance learning process (Bennett, 2011). The feedback from formative assessment has to be utilized to meet students learning goals and needs. It is argued that besides being authentic, competence-based assessment is learner-centered. Learner-centered assessment is the process of gathering information from many different sources in order to develop a deeper understanding of what students know, understand and can do with the knowledge as the result of their education experience (Kitta \& Tilya, 2010). The process culminates, when assessment results are used to improve subsequent learning (Huba \& Freed, 2000). Learner-centered approach to assessment need to be linked to the teaching and learning process.

Learner-centered assessment uses a variety of methods such as portfolios, practical tasks, oral examinations and performance assessments. It involves learners from its initial planning and provides continuous feedback to students, which leads to improved learning (Tilya \& Mafumiko, 2010). Assessment in Tanzania secondary schools still rely heavily on fact based examination (Mkimbili, 2018; Wandela, 2014). The final examination, which is prepared by an external body, has taken a dominant role in determining students' competence. The essence of having continuous assessment is to ensure that a student acquires appropriate knowledge and competences which are needed to determine the subsequent progression in further learning. In most of the secondary schools In Tanzania, assessment is done at the end of the term and at the end of the year where most of the instructional procedures are in their completion stage, hence the feedback from assessment fails to improve learning.

In order to attain the competencies in teaching and learning, the method of assessment ought also to change to make it more authentic. The focus should not be on passing the final examinations, but, rather, to attain competencies and ability in solving problems in real life situations (Mkimbili, 2018). In order to facilitate learners' acquisition of problem solving skills, in the continuous assessment, teachers should specify the learning tasks in a given lesson, administering the assessment for every aspect of competence learned and use feedback from evaluation to improve mastery of competencies (Tilya \& Mafumiko, 2010). There are a number of drawbacks to the implementation of competence-based continuous assessment in Tanzania. The revised syllabus claim to be competence- based but in reality it has too large content to be covered within a very short time. This situation forces teachers to use most of the time in ensuring the coverage of the content and do very little about the competencies to be attained. Teachers focus more on teaching students on how to answer the final examination papers (Osaki, 2004) and put less emphasis on continuous assessment. Traditional assessment where students answer multiple choice question examination does not allow for much variability in how students demonstrate the knowledge and skills they have acquired, that is competencies (Mueller, 2005). The question is how should continuous assessment in Tanzania secondary schools be practiced so as to facilitate the development of competencies among secondary students? This is the motive behind the writing of this paper.

\section{Competence-based Teaching and Assessment}

Competence-based science curriculum is the learning program whose major aim is to enhance students' understanding of scientific ideas, acquire appropriate skills and competences (Komba \& Mwandanji, 2015). This type of curriculum underscore the concept of competence which is defined as a combination of 
knowledge, skills, and attitudes which will enable individual students to carry out tasks to a required standard and be engaged in problem solving (Crawford, 2014). By being engaged in competence-based curriculum, students are expected to acquire specific knowledge and skills (Komba \& Mwandanji, 2015) and apply them in their ever day lives (Kafyulilo, Rugambuka, \& Moses, 2012). Competence-based curriculum emphasizes teaching students how to learn instead of just covering the content (Kitta \& Tilya, 2010). Teaching in this curriculum is learner-centered and constructivist oriented. The role of a teacher is to facilitate learning to designing learning activities that would enable learners to build the required knowledge and skills (Crawford, 2014).

Competence-based education alters the focus from grade oriented learning to meaningful learning characterised by frequent and constructive feedback, provided through continuous assessment (Abejehu, 2016). In other words, continuous assessment has abundant purposes to serve including improvement of teaching and learning process and motivating students to work harder and thus its success should be measured in terms of opportunities it provides for education quality enhancement. (Alemu, 2013) and (Chalchisa, 2014) contend that continuous assessment is a good practice for improving students' performance, monitoring students' learning progress, improving methods of teaching, motivating and grading students' achievement. To ensure effective teaching of subject matter and to help acquiring the required knowledge, skills and attitudes every teacher should maintain good practice of continuous assessment (Abejehu, 2016). In competence-base teaching and learning, students are provided with different tasks as continuous assessment to ensure the attainment of the required competences. Competence development is not only showing what you know but also applying the knowledge obtained in real life situation to solve the existing problem. Here assessment is encouraging learning experience in students; students accept timely support based on their individual learning needs (Abejehu, 2016).

Content-based teaching or rather traditional educational model emphasizes on the coverage of the content, that is, time-to-learn rather than mastery of the content (Nodine, 2016)). The teacher is the main source of knowledge, dominating the teaching and learning process. Students in this approach are taught in traditional way and assessment is conducted to determine students' acquisition of the facts from the material (Meyers, 2018). Teaching and learning process is teacher-centered and behaviourist oriented, where students are considered as recipient of knowledge. In the content-based teaching and learning process, teachers and students are striving to ensure the high performance in national examination and not to engage students in inquiry (Osaki, 2004). Teaching method is lecture where students learn through listening while the teacher is an expert delivering the content to the students (Boumová, 2008). This is opposite to competence-based teaching which emphasizes on hands-on- activities, student-led discovery and learnercentered activities (Boumová, 2008; Mkimbili, 2018). In content-based teaching there is either minimum or no interaction. In competence-based teaching, (learner-centered teaching) the teacher is a facilitator, students are in charge of their own learning, and they are active and problem solvers (Crawford, 2014; Mkimbili, 2018).

Competence-based assessment is a process in which an instructor works with a student to collect evidence of competence by means of set criteria of (Webber \& Tschepikow, 2013). In this assessment the students is required to indicate how they can use the knowledge acquired in solving real world problem (Webber \& Tschepikow, 2013). The students and the teacher in this approach share the objectives as well as the criteria for performance (Wolf, 1995). The teacher has to prepare the objectives and appropriate tasks which focus on attainment of competences. After preparing the task, the criteria to be used in marking the task should be shared between the teacher and the students. This kind of assessment is more of criterion referencing in nature where the performance of students is determined by the agreed criteria (Wolf, 1995). In this kind of assessment, a student may be required to do a series of tasks such as assignments, projects, tests, lab activities, portfolio (Webber \& Tschepikow, 2013). Doing a variety of tasks, make competence-based assessment both valid and authentic. Also competence based or outcome-based assessment, aimed at identifying learners' needs, planning the remedial learning for the needs, checking learners progress and supports their improvements (Kapambwe, 2010). 


\section{The Need for Continuous Assessment in Development of Competency}

Continuous assessment is an assessment procedure aimed at promoting students' learning (Shepard, 2005; Wiliam, 2011). For assessment to support learning it must focus on the gap between the current student's capabilities and the desired student's capability, and recommends approaches that can be utilized to bridge the gap (Wiliam, 2010, 2011). Continuous assessment is normally carried out during instruction. Its purpose is to improve teaching and learning (Abejehu, 2016). This approach to assessment guide students to develop competences. Meaningful learning occurs when assessment focuses on reflective learning rather than memorization of facts with little or no understanding (Shepard, 2005). If continuous assessment is planned for every aspect of learning, it can help in fostering understanding. Even slow learners can develop competences once the continuous assessment is appropriately designed.

Continuous feedback provided during formative assessment is crucial in competence development. The feedback directs the teacher on what to improve in teaching and the learners on what to concentrate more to attain the desired goals (Black \& Wiliam, 2009; Shepard, 2005). In formative assessment the results and feedback from assessment are used to adjust instruction (Black \& Wiliam, 2009; Shepard, 2005). In this way, assessment is part of instruction. This type of assessment is based on a variety of information sources such as portfolios, teacher's observation, project report and many other forms of alternative techniques. These ensure validity of the assessment as it is able to measure the larger sample of student's behaviour. Feedback that is provided during continuous assessment is crucial for supporting students' learning (SaliuAbdulahi, 2019). Continuous assessment provides students' progress for every sequence of activities. In continuous assessment teachers and students share the criteria of performance. Feedback in this assessment approach is provided by both the teacher and pees consequently, students are taking an active role in the assessment process (Saliu-Abdulahi, 2019). In continuous assessment a teacher can divide the learning experiences to be attained by the leaner into different tasks or activities. In this way, as the student is moving from one task to another, the required experiences or competences are being attained (Wiliam, 2010). This kind of assessment focuses on the process for attaining particular abilities or competences such as psychomotor steps in doing certain experiments. Continuous assessment is essential in competence based learning as activities are designed to develop a particular competence in phases.

To make continuous assessment useful in improving learning, one has to share with students, the targets expected of them. The students should be informed of what they are going to be assessed in that particular subject or lesson. The assessment should be shared among teachers and students to enable all of them to work hard towards the achievement of the planned goals. Apart from that, classroom assessment should be used to build confidence for the learners in their own learning (Stiggins, 2005). Leaner's confidence can be built by involving the learner in self-assessment as well as peer assessment. When learners are involved in the assessment process, they take responsibility for their own learning. A well-prepared rubric with the criteria for the performance can serve as a guide to self-assessment and peer assessment.

Besides, for a successful continuous assessment, classroom assessment results should be translated into frequent descriptive feedback (Stiggins, 2005). The information from assessment can be regarded as feedback, when it is structured to support future learning (Wiliam, 2011). Only grade that is provided with no information on what to be done to improve the performance is not sufficient feedback (Saliu-Abdulahi, 2019; Wiliam, 2011). Feedback from assessment can be utilized by the teacher in redesigning new approaches for teaching, and for students' and peers for further self-evaluation (Wiliam, 2011). The assessment feedback should be in a position to state the strengths and weaknesses of the assessment results. In continuous assessment results, learners need to be told on what is good in their work and what needs improvement. This will help them to improve their learning as well as attain competences. On top of that, teachers need to adjust instruction based on the results of the continuous assessment (Wiliam, 2011). For effective formative assessment the evidence obtained in the assessment process need to be interpreted and utilized for the better instructional practice (Wiliam, 2011). Teaching methods and techniques also need to be crosschecked to ensure that they fit the assessed content. 


\section{Challenges in Implementing Continuous Assessment in Tanzania Secondary Schools}

The competence-based of curriculum Tanzania underscore the significance of utilizing Formative assessment strategies such as portfolio, self-assessment, project work and problem solving tasks (Paulo, 2014; Paulo \& Tilya, 2014). Nevertheless, continuous assessment in secondary schools in Tanzania is far away from developing competence among secondary school students (Hardman, Ackers, Abrishamian, \& O'Sullivan, 2011; Paulo, 2014; Paulo \& Tilya, 2014). In most cases, teachers concentrate on ensuring coverage of the content of the curriculum as well as teaching students to answer national examination past paper questions. Most of the teachers assess students' performance four times per year as required by school regulations and not during instruction. Teachers normally give students mid- term test in April and September, terminal examinations in June and annual examinations which are usually done in November at the end of the academic year. These kind of assessment are not linked to the teaching process, thus they are summative in nature. Consequently, feedback from assessment fails to improve learning (Paulo \& Tilya, 2014). Tasks which students do in continuous assessment focus on questions at lower levels of the cognitive domain (Paulo \& Tilya, 2014). Assessment tools such as essays quizzes and practical task are rarely used in continuous assessment in Tanzania while self-assessment and oral examination are never used at all (Paulo, 2014). In this way, it is very difficult to develop student's competences. From this review we can argue that, continuous assessment aimed for the development of competences in Tanzania context is not sufficiently practices. Teachers in most cases are striving to ensure they cover the content, and use assessment to prepare students for final examinations. Scholars have noted various reasons for inadequate implementation of continuous assessment.

One of the reason for inadequate implementation of continuous assessment in Tanzania is inadequate skills of teachers on the use of formative assessment and in conducting competence-based assessment procedures (Paulo \& Tilya, 2014). Few individual teachers have acquired training on learner centered assessment, but most of the training attended by teachers are not continuous as the participants learnt only a few leanercentered assessment techniques. Since teachers lack adequate knowledge on how to develop assessment tools, it is very difficult for the continuous assessment to be useful for competence development (Mpapalika, 2014).

Besides, it was observed from the 2010 syllabuses that the content to be covered in different subjects, particularly sciences is too long to be covered within the prescribed time (Mpapalika, 2014) This forces teachers to concentrate on the coverage of the content rather than developing problem solving skills to students (Mkimbili, 2018). Some assessment tools which are useful in competence development such as projects, portfolio, outdoor activities as well as practical work are rarely used (Paulo, 2014). In most cases, teachers provide tests which emphasize on memorization of facts and information which are in the lower levels of Bloom's Taxonomy (Mkimbili, 2018; Wandela, 2014). There is no sufficient constructive feedback which is provided to students regarding their performance (Paulo, 2014). Teachers are providing mostly short evaluative comments with no directive on what to improve, consequently assessment can hardly be utilized to improve teaching (Saliu-Abdulahi, 2019). Teachers fail to provide effective continuous assessment for their students since they have a lot to be covered within a very short time. This encourages superficial learning as teacher does not have enough time even to tell the students what should be done to improve.

High teacher-student ratio especially in science subjects is another obstacle towards the competence-based continuous assessment (Mpapalika, 2014). Due to the fact that teachers are overloaded with various responsibilities, they fail to conduct effective continuous assessment (Paulo, 2014). For example a teacher who is teaching mathematics in a class with more than 200 students cannot provide effective continuous assessment as well as constructive feedback. The teacher cannot integrate assessment in the teaching and learning process.

Inadequacy of teaching materials is another obstacle towards implementing competence-based continuous assessment. Teachers fail to use different teaching approaches due to inadequate teaching and learning 
Mkimbili et al., Adv. J Social Sci.; Vol. 6 Issue 1, pp: 64-70, 2020

materials like books, laboratories and others (Mkimbili, 2018; Mpapalika, 2014).Consequently, in most science classroom teacher-directed activities such as teacher questioning, teacher explanations and writing notes for students dominates (Hardman et al., 2011). With inadequate teaching and learning materials, teachers can fail to design the assessment tool appropriate for measuring and developing competences.

\section{Conclusion}

The use of continuous assessment in secondary schools, aimed at competence development is very crucial for prosperous education any country. Competent students are in the position to be future experts in various fields and contribute to the country's economic development. In order to achieve this, substantial changes need to take place in the assessment procedures in Tanzania. Continuous assessment procedures should be restructured in such a way that they go beyond paper-and-pencil tests. Continuous assessment should be integrated into the teaching and learning process. It should be learner-centered and should employ various assessment techniques including among others, project work, assay writing, oral examinations and portfolio assessment. To be able to develop assessment tasks relevant for enhancing problem solving skills to students, teachers in Tanzania require training on the use of questioning techniques and assessment tasks for learner-centered teaching. Teachers need adequate knowledge on how to conduct effective continuous assessment. The capacity building process should be planned continuously to ensure that teachers acquire the appropriate skills on how to prepare assessment tools, how to provide constructive feedback to students, and how to apply various assessment tools for competence development. Questions and tasks provided to leaners need to go beyond the memorization of scientific facts and concepts, to ensure learners' development of competences. From this review we noted that huge content that is prescribed to be covered in a limited time is a key obstacle for the implementation of learner-centered assessment approaches. Consequently we argue that, a comprehensive curriculum review is of paramount importance to make sure the planned content matches with the time allocated so as to enable teachers perform effective continuous assessment. The content should not be too big to be covered. This will encourage learning for understanding rather than superficial learning.

Likewise, we have noted that limited resources and overcrowded constrained the implementation of learnercentered assessment approaches. Therefore more teachers, especially in science and mathematics should be prepared to ensure an appropriate teacher-student ratio. Teacher preparation need to include training on how local available resources can be utilized for engaging students in critical thinking and problem solving. Teachers who are well trained and motivated can engage students in inquiry-based science teaching in a place with limited resources. Having an appropriate teacher-student ratio, will give room for teachers to prepare authentic assessment tools for continuous assessment. Also, teachers will have ample time to give constructive feedback to their students. Schools should be provided with sufficient teaching and learning resources such as laboratories, books, libraries, and other necessary materials to ensure quality teaching and learning coupled with appropriate continuous assessment. This will ultimately lead to preparation of secondary school graduates who are problem solvers rather than just absorbers of knowledge. More research is needed particular in Tanzania context with regards to approaches for enhancing learner-centered continuous assessment in schools with limited resources and congested classrooms.

\section{Competing Interest}

The authors declared that no conflict of interest exist in this publication.

\section{How to Cite this Article:}

Mkimbili, S., \& Kitta, S. K. (2019). The Rationale of Continuous Assessment for Development of Competencies in Tanzania Secondary Schools. Advanced Journal of Social Science, 6(1), 64-70. doi: 10.21467/ajss.6.1.64-70

\section{References}

Abejehu, S. B. (2016). The Practice of Continuous Assessment in Primary Schools: The Case of Chagni, Ethiopia. Journal of Education and Practice, 7(31), 24-30. 
The Rationale of Continuous Assessment for Development of Competencies in Tanzania Secondary Schools

Alemu, B. M. (2013). Continous assessment issues and practice in secondary schools of Oromia regional state of Ethiopia: The big picture of assessment mechanism. Palgo.J.Edu.Research.

Bennett, R. E. (2011). Formative assessment: A critical review. Assessment in Education: Principles, Policy \& Practice, $18(1)$, 5-25.

Black, P., \& Wiliam, D. (2009). Developing the theory of formative assessment. Educational Assessment, Evaluation and Accountability (formerly: Journal of Personnel Evaluation in Education), 21(1), 5.

Boumová, V. (2008). Traditional vs. modern teaching methods: Advantages and disadvantages of each. Masarykova univerzita, Filozofická fakulta.

Chalchisa, D. (2014). Practices of Assessing Graduate Students' Learning Outcomes in Selected Ethiopian Higher Education Institutions. Journal of International Cooperation in Education, 16 (2): 157, 180.

Crawford, B. A. (2014). From inquiry to scientific practices in the science classroom. In N. Lederman \& S. Abell (Eds.), Hand book of Research in science education (Vol. 2, pp. 515-541). New York:: Rutledge.

Hardman, F., Ackers, J., Abrishamian, N., \& O'Sullivan, M. (2011). Developing a systemic approach to teacher education in sub-Saharan Africa: Emerging lessons from Kenya, Tanzania and Uganda. Compare: A Journal of Comparative and International Education, 41(5), 669-683.

Huba, M. E., \& Freed, J. E. (2000). Learner-centered assessment on college campuses: Shifting the focus from teaching to learning: ERIC. Retrieved from https://eric.ed.gov/?id=ED438867

Kafyulilo, A. C., Rugambuka, I. B., \& Moses, I. (2012). The implementation of competency based teaching approaches in Tanzania: The case of pre-service teachers at Morogoro Teachers Training College. Universal Journal of Education and General Studies, 1(11), 339347.

Kapambwe, W. M. (2010). The implementation of school based continuous assessment (CA) in Zambia. Educational Research and Reviews, $5(3), 099-107$.

Kitta, S., \& Tilya, F. (2010). The status of learner-centred learning and assessment in Tanzania in the context of the competence-based curriculum. Papers in Education and Development(29), 77-91.

Komba, S. C., \& Mwandanji, M. (2015). Reflections on the implementation of competence based cuurriculum in Tanzanian secondary schools.

Meyers, J. L. (2018). Scoring models in competency-based educational assessment. The Journal of Competency-Based Education, 3(3), e01173.

Mkimbili, S. T. (2018). Learner-Centred Science Teaching in Community Secondary Schools in Tanzania. (PhD), University of Oslo. Retrieved from https://www.duo.uio.no/handle/10852/60279

MoEV. (2007). Chemistry syllabus for secondary schools. Dar es Salaam: Tanzania Institute of Education.

Mpapalika, K. M. (2014). Tanzania science teachers' practices and challenges in continuous assessment.

Mueller, J. (2005). The authentic assessment toolbox: enhancing student learning through online faculty development. Journal of Online Learning and Teaching.

Nodine, T. (2016). How did we get here? A brief history of competency-based higher education in the United States. The Journal of Competency-Based Education, 1(1), 5-11.

Ogunniyi, M., \& Rollnick, M. (2015). Pre-service science teacher education in Africa: Prospects and challenges. Journal of Science Teacher Education, 26(1), 65-79.

Osaki, K. M. (2004). Reflections on the state of science education in Tanzania. In K. H. K. M. Osaki, \&W. Ottevanger (Ed.), Reforming science and mathematics education in Sub-Saharan Africa (pp. 11-26). Dar es salaam: Team Project.

Osborne, J., \& Dillon, J. (2008). Science education in Europe: Critical reflections (Vol. 13): London: The Nuffield Foundation.

Paulo, A. (2014). Pre-service teachers' preparedness to implement competence-based curriculum in secondary schools in Tanzania. International Journal of Education and Research, 2(7), 219-230.

Paulo, A., \& Tilya, F. (2014). The 2005 secondary school curriculum reforms in Tanzania: Disjunction between policy and practice in its implementation. Journal of Education and Practice, 5(35), 114-122.

Saliu-Abdulahi, D. (2019). Teacher and Student Perceptions of Current Feedback Practices in English Writing Instruction. (PhD), University of Oslo. Retrieved https://www.duo.uio.no/handle/10852/66784

Shepard, L. A. (2005). Formative assessment: Caveat emptor. Paper presented at the ETS Invitational Conference The Future of Assessment: Shaping Teaching and Learning, New York.

Stiggins, R. (2005). From formative assessment to assessment for learning: A path to success in standards-based schools. Phi Delta Kappan, 87(4), 324-328.

Tilya, F., \& Mafumiko, F. (2010). The compatibility between teaching methods and competence-based curriculum in Tanzania. Papers in Education and Development(29), 37-56.

Wandela, E. L. (2014). Tanzania Post-colonial educational system and perspectives on secondary science education, pedagogy, and curriculum: a qualitative study.

Webber, K. L., \& Tschepikow, K. (2013). The role of learner-centred assessment in postsecondary organisational change. Assessment in Education: Principles, Policy \& Practice, 20(2), 187-204.

Wiliam, D. (2010). The role of formative assessment in effective learning environments. In H. Dumont, D. Instance, \& F. Benavides (Eds.), The nature of learning: Using research to inspire practice (pp. 135-155): OECD.

Wiliam, D. (2011). What is assessment for learning? Studies in educational evaluation, 37(1), 3-14.

Wolf, A. (1995). Competence-based assessment: McGraw-Hill Education (UK). Retrieved from http://www.national-training.com/library/6Wolf-report-on-competence-based-assessment.pdf

Publish your research article in AIJR journals-

$\checkmark$ Online Submission and Tracking

$\checkmark$ Peer-Reviewed

$\checkmark \quad$ Rapid decision

$\checkmark \quad$ Immediate Publication after acceptance

$\checkmark \quad$ Articles freely available online

$\checkmark \quad$ Retain full copyright of your article.

Submit your article at journals.aijr.in
Publish your books with AIJR publisherPublish with ISBN and DOI.

$\checkmark \quad$ Publish Thesis/Dissertation as Monograph.

$\checkmark \quad$ Publish Book Monograph.

$\checkmark \quad$ Publish Edited Volume/ Book.

$\checkmark \quad$ Publish Conference Proceedings Retain full copyright of your books.

Submit your manuscript at books.aijr.org 